\title{
EXTRAORDINARY FACTS
}

\author{
relating to the
}

\section{Vision of Colours:}

WITH OBSERVATIONS.

$$
\begin{gathered}
\text { BY MR. } 70 H N \text { DALTON. } \\
\text { READ OCT. } 31 \mathrm{sT}, 1794 .
\end{gathered}
$$

\section{It has been observed, that our ideas of colours,} sounds, tastes, \&c. excited by the same object may be very different in themselves, without our being aware of it; and that we may nevertheless converse intelligibly concerning such objects, as if we were certain the impressions made by them on our minds were exactly similar. All, indeed, that is required for this purpose, is, that the same object should uniformly make the same impression on each mind; and that objects which appear different to one should be equally so to others. It will, however, scarcely be supposed, that any two objects, which are every day before us, should appear hardly distinguishable to one person, and very different to another, without the circumstance immediately suggesting a difference in their faculties of vision; yet such is the fact, not only with regard to myself, but to many others also, as will appear in the following account.

I was always of opinion, though I might not of- 
ten mention it, that several colours were injudiciously named. The term pink, in reference to the flower of that name, seemed proper enough; but when the term red was substituted for pink, I thought it highly improper; it should have been blue, in my apprehension, as pink and blue appear to me very nearly allied; whilst pink and red have scarcely any relation.

In the course of my application to the sciences, that of optics necessarily claimed attention; and I became pretty well acquainted with the theory of light and colours before I was apprized of any peculiarity in my vision. I had not, however, attended much to the practical discrimination of colours, owing, in some degree, to what I conceived to be a perplexity in their nomenclature. Since the year 1790, the occasional study of botany obliged me to attend more to colours than before. With respect to colours that were white, yellow, or green, I readily assented to the appropriate term. Blue, purple, pink, and crimson appeared rather less distinguishable; being, according to my idea, all referable to blue. I have often seriously asked a person whether a flower was blue or pink, but was generally considered to be in jest. Notwithstanding this, I was never convinced of a peculiarity in my vision, till I accidentally observed the colour of the flower of the Geranium zonale by candle-light, in the Autumn of 1792. The flower was pink, but it appeared to me almost an exact 
sky-blue by day; in candle-light, however, it was astonishingly changed, not having then any blue in it, but being what I called red, a colour which forms a striking contrast to blue. Not then doubting but that the change of colour would be equal to all, I requested some of my friends to observe the phænomenon; when I was surprised to find they all agreed, that the colour was not materially different from what it was by day-light, except my brother who saw it in the same light as myself. This observation clearly proved, that my vision was not like that of other persons; - and, at the same time, that the difference between day-light and candlelight, on some colours, was indefinitely more perceptible to me than to others. It was nearly two years after that time, when I entered upon an investigation of the subject, having procured the assistance of a friend, who, to his acquaintance with the theory of colours, joins a practical knowledge of their names and constitutions. I shall now proceed to state the facts ascertained under the three following heads :

I. An account of my own vision.

II. An account of others whose vision has been found similar to mine.

III. Observations on the probable cause of our anomalous vision.

\section{OF MY OWN VISION.}

It may be proper to observe, that I am short- 
sighted. Concave glasses of about five inches focus suit me best. I can see distinctly at a proper distance; and am seldom hurt by too much or too little light; nor yet with long application.

My observations began with the solar spectrum, or coloured image of the sun, exhibited in a dark room by means of a glass prism. I found that persons in general distinguish six kinds of colour in the solar image; namely, red, orange, yellow, green, blue, and purple. Newton, indeed, divides the purple into indigo and violet; but the difference between him and others is merely nominal. To me it is quite otherwise:-I see only two or at most three distinctions. These I should call yellow and blue; or yellow, blue, and purple. My yellow comprehends the red, orange, yellow, and green of others; and my blue and purple coincide with theirs. That part of the image which others call red, appears to me little more than a shade, or defect of light; after that the orange, yellow, and green seem one colour, which descends pretty uniformly from an intense to a rare yellow, making what I should call different shades of yellow. The difference between the green part and the part is very striking to my eye: they seem to be strongly contrasted. That between the blue and purple is much less so. The purple appears to be blue much darkened and condensed. In viewing the flame of a candle by night through the prism, the appearances are pretty much the same, 
except that the red extremity of the image appears more vivid than that of the solar image.

I now proceed to state the results of my observations on the colours of bodies in general, whether natural or artificial, both by day-light and candlelight. I mostly used ribbands for the artificial colours.

\section{RED. \\ (By day-light.)}

Under this head I include crimson, scarlet, red, and pink. All crimsons appear to me to consist chiefly of dark blue; but many of them seem to have a strong tinge of dark brown. I have seen specimens of crimson, claret, and mud, which were very nearly alike. Crimson has a grave appearance, being the reverse of every shewy and splendid colour. Woollen yarn dyed crimson or dark blue is the same to me. Pink seems to be composed of nine parts of light blue, and one of red, or some colour which has no other effect than to make the light blue appear dull and faded a little. Pink and light blue therefore compared together, are to be distinguished no otherwise than as a splendid colour from one that has lost a little of its splendour. Besides the pinks, roses, \&c. of the gardens, the following British flora appear to me blue; namely, Statice Armeria, Trifolium pratense, Lychnis Flos-cuculi, Lychnis dioica, and many of the Gerania. The colour of a florid complexion ap- 
pears to me that of a dull, opake, blackish blue, upon a white ground. A solution of sulphate of iron in the tincture of galls (that is, dilute black ink) upon white paper, gives a colour much resembling that of a florid complexion. It has no resemblance of the colour of blood. Red and scarlet form a genus with me totally different from pink. My idea of red I obtain from vermilion, minium, sealing wax, wafers, a soldier's uniform, \&c. These seem to have no blue whatever in them. Scarlet has a more splendid appearance than red. Blood appears to me red; but it differs much from the articles mentioned above. It is much more dull, and to me is not unlike that colour called bottle-green. Stockings spotted with blood or with dirt would scarcely be distinguishable.

\section{RED. \\ (By candle-light.)}

Red and scarlet appear much more vivid than by day. Crimson loses its blue and becomes yellowish red. Pink is by far the most changed; indeed it forms an excellent contrast to what it is by day. No blue now appears; yellow has taken its place. Pink by candle-light seems to be three parts yellow and one red, or a reddish yellow. The blue, however, is less mixed by day than the yellow by night. Red, and particularly scarlet, is a superb colour by candle-light; but by day some reds are VOL, v. 
the least shewy imaginable: I should call them dark drabs.

\section{ORANGE \& YELLOW. \\ (By day-light and candle-light.)}

I do not find that I differ materially from other persons in regard to these colours. I have sometimes seen persons hesitate whether a thing was white or yellow by candle-light, when to me there was no doubt at all.

\section{GREEN.$$
\text { (By day-light.) }
$$

I take my standard idea from grass. This apapears to me very little different from red. The face of a laurel-leaf (Prunus Lauro-cerasus) is a good match to a stick of red sealing-wax; and the back of the leaf answers to the lighter red of wafers. Hence it will be immediately concluded, that I see either red or green, or both, different from other people. The fact is, I believe that they both appear different to me from what they do to others. Green and orange have much affinity also. Apple green is the most pleasing kind to me; and any other that has a tinge of yellow appears to advantage. I can distinguish the different vegetable greens one from another as well as most people; and those which are nearly alike or very unlike to others are so to me. A decoction of bohea tєa. a solution of liver of sulphur, ale, \&c. \&c. which 
others call brown, appear to me green. Green woollen cloth, such as is used to cover tables, appears to me a dull, dark, brownish red colour. A mixture of two parts mud and one red would come near it. It resembles a red soil just turned up by the plough. When this kind of cloth loses its colour, as other people say, and turns yellow, then it appears to me a pleasant green. Very light green paper, silk, \&c. is white to me.

\section{GREEN. (By candle-light.)}

I agree with others, that it is difficult to distinguish greens from blues by candle-light; but, with me, the greens only are altered and made to approach the blues. It is the real greens only that are altered in my eye; and not such as I confound with them by day-light, as the brown liquids abovementioned, which are not at all tinged with blue by candle-light, but are the same as by day, except that they are paler.

BLUE.

(By day-light and candle-light.)

I apprehend this colour appears very nearly the same to me as to other people, both by day-light and candle-light.

PURPLE.

(By day-light and candle-light.)

This seems to me a slight modification of blue, 
I seldom fail to distinguish purple from blue; but should hardly suspect purple to be a compound of blue and red. The difference between day-light and candle-light is not material.

\section{MISCELLANEOUS OBSERVATIONS.}

Colours appear to me much the same by moonlight as they do by candle-light. *

Colours viewed by lightning appear the same as by day-light; but whether exactly so, I have not ascertained.

Colours seen by electric light appear to me the same as by day-light. That is, pink appears blue, \&c.

Colours viewed through a transparent sky-blue liquid, by candle-light, appear to me as well as to others the same as by day-light.

Most of the colours called drabs appear to me the same by day-light and candle-light.

A light drab woollen cloth seems to me to resemble a light green by day. These colours are, however, easily distinguished by candle-light, as the latter becomes tinged with blue, which the former does not. I have frequently seen colours of the drab kind, said to be nearly alike, which appeared to me very different.

* Mr. Boyle observed colours by moon-light to differ from those by day-light. Priestley on Vision, p. 145. 
My idea of brown I obtain from a piece of white paper heated almost to ignition. This colour by day-light seems to have a great affinity to green, as may be imagined from what I have said of greens. Browns seem to me very diversified; some I should call red:-dark brown woollen cloth I should call black.

The light of the rising or setting sun has no particular effect; neither has a strong or weak light. Pink appears rather duller, all other circumstances alike, in a cloudy day.

All common combustible substances exhibit colours to me in the same light; namely, tallow, oil, wax, pit-coal.

My vision has always been as it is now.

\section{AN ACCOUNT OF OTHERS WHOSE VISION HAS BEEN FOUND SIMILAR TO MINE.}

It has been already observed that my brother perceived the change in the colour of the geranium such as myself. Since that time having made a great number of observations on colours, by comparing their similarities, \&c. by day-light and candle-light, in conjunction with him, I find that we see as nearly alike as any other persons do. $\mathrm{He}$ is shorter sighted than myself.

As soon as these facts were ascertained, I conceived the design of laying our case of vision before 
the public, apprehending it to be a singular one. I remembered, indeed, to have read in the Philosophical Transactions for 1777 , an account of $M r$. Harris of Maryport in Cumberland,* who, it was said, "could not distinguish colours;" but his case appeared to be different from ours. Considering, however, that one anomaly in vision may tend to illustrate another, I reperused the account; when it appeared extremely probable that if his vision had been fully investigated, and a relation of it given in the first person, he would have agreed with me. There were four brothers in the same predicament, one of whom is now living. Having an acquaintance in Maryport, I solicited him to propose a few queries to the survivor, which he readily did (in conjunction with another brother, whose vision has nothing peculiar), and from the answers transmitted to me, I could no longer doubt of the similarity of our cases. To render it still more circumstantial, I sent about twenty specimens of different coloured ribbands, with directions to make observations upon them by day-light and candle-light: the result was exactly conformable to my expectation.

It then appeared to me probable, that a considerable number of individuals might be found whose

* A transiation of this account, to which is annexed the extraordinary case of M. Colardeau, is inserted in Rozie R: Observations sur la Physique, Ec. p. 87. E. H. 


\section{On the Vision of Colours.}

vision differed from that of the generality, but at the same time agreed with my own. Accordingly I have since taken every opportunity to explain the circumstances amongst my acquaintance, and have found several in the same predicament. Only one or two I have heard of who differ from the generality and from us also. It is remarkable that, out of twenty-five pupils I once had, to whom I explained this subject, two were found to agree with me; and, on another similar occasion, one. Like myself, they could see no material difference betwixt pink and light blue by day, but a striking contrast by candle-light. And, on a fuller investigation, I could not perceive they differed from me materially in other colours. They, like all the rest of us, were not aware of their actually seeing colours different from other people; but imagined there was great perplexity in the names ascribed to particular colours. I think I have been informed already of nearly twenty persons whose vision is like mine. The family at Maryport consisted of six sons and one daughter; four of the sons were in the predicament in question. Our family consisted of three sons and one daughter who arrived at maturity; of whom two sons are circumstanced as I have described. The others are mostly individuals in families, some of: which are numerous. I do not find that the parents or children in any of the instances have been so, unless in one case. Nor have I been able to discover any physical cause whatever for it. Our 
vision, except as to colours, is as clear and distinct as that of other persons. Only two or three are short sighted. It is remarkable that I have not heard of one female subject to this peculiarity.

From a great variety of observations made with many of the abovementioned persons, it does not appear to me that we differ more from one another than persons in general do. We certainly agree in the principal facts which characterize our vision, and which I have attempted to point out below. It is but justice to observe here, that several of the resemblances and comparisons mentioned in the preceding part of this paper were first suggested to me by one or other of the parties, and found to accord with my own ideas.

\section{CHARACTERISTIC FACTS OF OUR VISION.}

1. In the solar spectrum three colours appear, yellow, blue, and purple. The two former make a contrast; the two latter seem to differ more in degree than in kind.

2. Pink appears, by day-light, to be sky-blue a little faded; by candle-light it assumes an orange or yellowish appearance, which forms a strong contrast to blue.

3. Crimson appears a muddy blue by day; and crimson woollen yarn is much the same as dark blue.

4. Red and Scarlet have a more vivid and fla. ming appearance by candle-light than by day-ligh 


\section{On the Vision of Colours.}

5. There is not much difference in colour between a stick of red sealing wax and grass, by day.

6. Dark green woollen cloth seems a muddy red, much darker than grass, and of a very different colour. blue.

7. The colour of a florid complexion is dusky

8. Coats, gowns, \&c. appear to us frequently to be badly matched with linings, when others say they are not. On the other hand, we should match crimsons with claret or mud; pinks with light blues; browns with reds; and drabs with greens.

9. In all points where we differ from other persons, the difference is much less by candle-light than by day-light.

\section{OBSERVATIONS TENDING TO POINT} OUT THE CAUSE OF OUR ANOMALOUS VISION.

The first time I was enabled to form a plausible idea of the cause of our vision, was after observing that a sky-blue transparent liquid modified the light of a candle so as to make it similar to day-light; and, of course, restored to pink its proper colour by day, namely, light blue. This was an important observation. At the same time that it exhibited the effect of a transparent coloured medium in the modification of colours, it seemed to indicate 
the analogy of solar light to that resulting from combustion; and that the former is modified by the transparent blue atmosphere, as the latter is by the transparent blue liquid. Now the effect of a transparent coloured medium, as Mr. Delaval has proved, is to transmit more, and consequently imbibe fewer of the rays of its own colour, than of those of other colours. Reflecting upon these facts, I was led to conjecture that one of the humours of my eye must be a transparent, but coloured, medium, so constituted as to absorb red and green rays principally, because I obtain no proper ideas of these in the solar spectrum; and to transmit blue and other colours more perfectly. What seemed to make against this opinion however was, that I thought red bodies, such as vermilion, should appear black to me, which was contrary to fact. How this difficulty was obviated will be understood from what follows.

Newton has sufficiently ascertained, that opake bodies are of a particular colour from their reflecting the rays of light of that colour more copiously than those of the other colours; the unreflected rays being absorbed by the bodies. Adopting this fact, we are insensibly led to conclude, that the more rays of any one colour a body reflects, and the fewer of every other colour, the more perfect will be the colour. This conclusion, however, is certainly erroneous. Splendid coloured bodies reflect light of every colour copiously; but that of their own most 
so. Accordingly we find, that bodies of all colours, when placed in homogeneal light of any colour, appear of that particular colour. Hence a body that is red may appear of any other colour to an eye that does not transmit red, according as those other colours are more copiously reflected from the body, or transmitted through the humours of the eye.

It appears therefore almost beyond a doubt, that one of the humours of my eye, and of the eyes of my fellows, is a coloured medium, probably some modification of blue. I suppose it must be the vitreous humour; otherwise I apprehend it might be discovered by inspection, which has not been done. It is the province of physiologists to explain in what manner the humours of the eye may be coloured, and to them I shall leave it; and proceed to shew that the hypothesis will explain the facts stated in the conclusion of the second part.

1. This needs no further illustration.

2. Pink is known to be a mixture of red and blue; that is, these two colours are reflected in excess. Our eyes only transmit the blue excess, which causes it to appear blue; a few red rays pervading the eye may serve to give the colour that faded appearance. In candle-light, red and orange, or some other of the higher colours, are known to abound more proportionably than in day-light. The orange light reflected may therefore exceed the blue, and the compound colour consist of red and orange. 
Now, the red being most copiously reflected, the colour will be recognized by a common eye under this small modification; but the red not appearing to us, we see chiefly the orange excess: it is consequently to us not a modification but a new colour.

3. By a similar method of reasoning, crimson, being compounded of red and dark blue, must assume the appearances I have described.

4. Bodies that are red and scarlet probably reflect orange and yellow in greatest plenty, next after red. The orange and yellow, mixed with a few red rays, will give us our idea of red, which is heightened by candle-light, because the orange is then more abundant.

5. Grass-green is probably compounded of green, yellow, and orange, with more or less blue. Our idea of it will then be obtained pi incipally from the yellow and orange mixed with a few green rays. It appears, therefore, that red and green to us will be nearly alike. I do not, however, understand, why the greens should assume a bluish appearance to us and to every body else, by candle-light, when it should seem that candle-light is deficient in blue.

6 . The green rays not being perceived by us, the remaining rays may, for aught that is known, compound a muddy red.

7. The observations upon the phænomena of pink and crimson, will explain this fact. 


\section{On the Vision of Colours.}

8. Suppose a body to reflect red rays as the number 8 , orange rays as the number 6 , and blue as 5 ; and another body red 8 , orange 6 , and blue 6 : then it is evident that a common eye, attending principally to the red, would see little difference in those colours; but we, who form our ideas of the colours from the orange and blue, should perceive the latter to be bluer than the former.

9. From the whole of this paper it is evident, that our eyes admit blue rays in greater proportion than those of other people; therefore when any kind of light is less abundant in blue, as is the case with candle-light compared to day-light, our eyes serve in some degree to temper that light, so as to reduce it nearly to the common standard. This seems to be the reason why colours appear to us by candlelight, almost as they do to others by day-light.

I shall conclude this paper by observing, that it appears to me extremely probable, that the sun's light and candle-light, or that which we commonly obtain from combustion, are originally constituted alike; and that the earth's atmosphere is properly. a blue fluid, and modifies the sun's light so as to occasion the commonly perceived difference. 


\section{$2 \mathrm{BHL}$ Biodiversity Heritage Library}

Dalton, John. 1798. "Extraordinary facts relating to the vision of colours: with observations." Memoirs of the Literary and Philosophical Society of Manchester 5(1), 28-45.

View This Item Online: https://www.biodiversitylibrary.org/item/52767

Permalink: https://www.biodiversitylibrary.org/partpdf/308502

\section{Holding Institution}

Natural History Museum Library, London

\section{Sponsored by}

Natural History Museum Library, London

\section{Copyright \& Reuse}

Copyright Status: Public domain. The BHL considers that this work is no longer under copyright protection.

License: http://creativecommons.org/licenses/by-nc/3.0/

This document was created from content at the Biodiversity Heritage Library, the world's largest open access digital library for biodiversity literature and archives. Visit BHL at https://www.biodiversitylibrary.org. 